\title{
PRIVACIDADE VERSUS SEGURANÇA PÚBLICA: O ACESSO AO CONTEÚDO DE CELULAR PELA AUTORIDADE POLICIAL
}

José Antonio Remedio ${ }^{1}$

Bruno Henrique Salviano Silva ${ }^{2}$

\section{Resumo}

A pesquisa tem por objeto analisar a relação existente entre o direito à privacidade e o direito à segurança pública, com ênfase à apreensão e ao acesso aos dados de aparelho celular pela autoridade policial, no exercício da persecução penal, sem autorização judicial. A matéria é atual, importante e controvertida, inclusive porque o Supremo Tribunal Federal, na Repercussão Geral no Recurso Extraordinário com Agravo 1.042.075-RJ, em fase de julgamento, reconheceu em 2017 a repercussão geral em relação ao tema referente à perícia realizada pela autoridade policial em aparelho celular encontrado no local do crime, com acesso à agenda telefônica e ao registro de chamadas, sem autorização judicial. O método utilizado é o indutivo, com base na legislação, doutrina e jurisprudência. Tem-se, em conclusão, que o acesso aos dados de aparelho celular apreendido pela autoridade policial no exercício da persecução penal, inclusive no caso de prisão em flagrante do infrator, está condicionado à prévia autorização judicial, embora em casos urgentes ou excepcionais seja admissível o acesso sem anterior autorização, caso em que deverá ser informada a autoridade judicial logo que possível para o exercício do controle do ato, legitimando-se constitucionalmente a restrição exercida em relação ao direito fundamental à privacidade.

Palavras-chave: Acesso aos Dados de Celular; Comunicação; Direito à Privacidade; Direito à Segurança Pública; Privacidade.

\footnotetext{
${ }^{1}$ Doutor em Direito do Estado pela Pontifícia Universidade Católica de São Paulo (PUCSP). Professor de Graduação e Pósgraduação (Mestrado) em Direito da Universidade Metodista de Piracicaba (UNIMEP). Professor de Graduação em Direito do Centro Universitário Adventista de São Paulo (UNASP). E-mail: jaremedio@yahoo.com.br.

${ }^{2}$ Mestrando em Direito pela Universidade Metodista de Piracicaba (UNIMEP). Professor de Graduação em Direito do Centro Universitário Adventista de São Paulo (UNASP).E-mail: bruno.cwf@gmail.com
} 


\section{INTRODUÇÃO}

O ser humano possui propensão para se relacionar com outros indivíduos, havendo para isso envolvimento, aproximação e atenção entre as pessoas, e a comunicação é inerente a essa interação.

A comunicação é indissociável dos relacionamentos e da vida em sociedade. Para José Afonso da Silva (2007, p. 90), o homem não vive concentrado apenas em seu espírito, não vive isolado, razão por que por sua natureza é um ente social, tendo "a viva tendência e necessidade de expressar e trocar suas ideias e opiniões com outros homens, de cultivar mútuas relações, seria mesmo impossível vedar, porque fora para isso necessário dissolver e proibir a sociedade". No decorrer da existência do ser humano, a comunicação sempre esteve presente, normalmente por meio de símbolos, signos, figuras, gestos ou palavras.

Com a modernidade e o desenvolvimento da técnica, houve aprimoramento em muitos seguimentos da vida, e na comunicação não foi diferente, principalmente com o surgimento da internet, que viabilizou o estreitamento das fronteiras entre as pessoas, possibilitando uma universalidade comunicacional em ambiente virtual, transcendendo os limites impostos pelo tempo e espaço.

Há várias formas de realização de comunicação, como entre um indivíduo e outro, entre grupos sociais e até mesmo com as massas de indivíduos. Dentre outras formas, isso se dá através de cartas físicas, cartas virtuais, sinais, gestos, expressões faciais, e-mail e aplicativos que viabilizam o diálogo. Hoje, a maioria dos instrumentos comunicacionais está ligada ao desenvolvimento e sofisticação tecnológicos, como Whatsapp, MySMS, Kik, QKSMS, Mighty Text, Skype, Snapchat, Facebook Messenger, HoverChat, TextSecure, Textra SMS, GoSMS Pro, Evolve SMS, Im+, WeChat, BBM, Viber, Ebuddy, ooVoo, Handcent SMS, Clipchat, ChatON, Hello SMS e ChompSMS.

A propulsão de tecnologias que possibilitam a ampliação dos instrumentos de comunicação só tende a aumentar. $\mathrm{O}$ indivíduo, quando se comunica, o faz pessoal ou virtualmente, podendo o destinatário ser individual ou coletivo.

$\mathrm{O}$ ato de falar sugere, à primeira vista, um liame com a privacidade do indivíduo, aí compreendidas a intimidade, a vida privada e o segredo, visto que comunicação implica em racionalização, filtragem de conteúdo, escolha do que comunicar.

Todavia, é preciso investigar se o direito personalíssimo à privacidade incide sobre qualquer forma de comunicação, ou seja, sobre a comunicação privada e a comunicação pública ou dirigida às massas.

O celular é um dos instrumentos viabilizadores da comunicação, principalmente privada. A privacidade na comunicação é maculada quando, sem o desejo ou o consentimento do dono, terceiros acabam acessando o conteúdo existente no aparelho, ainda que no exercício do dever constitucional da segurança pública pelas 
autoridades policiais (CF/88, art. $144 \mathrm{da} \mathrm{CF/88),}{ }^{3}$ que compreende a atividade persecutória estatal pela Polícia. ${ }^{4}$

Desta forma, há um potencial conflito de direitos, de um lado, o direito fundamental à privacidade (art. $5^{\circ}$, X e XII, da CF/88), incidente nos instrumentos que viabilizam a comunicação, e de outro, o direito social à segurança pública (arts. $6^{\circ}$ e 144 da CF/88), no qual se insere a persecução criminal.

Nesse contexto, é possível questionar se a autoridade policial pode acessar o conteúdo de aparelho celular apreendido quando da prática de crime, se existe algum regramento para isso e se a prisão do indivíduo e a apreensão do celular autorizam a devassa do conteúdo do aparelho.

A matéria tem gerado grande controvérsia na jurisprudência, tanto que o Supremo Tribunal Federal, em 23-11-2017, na Repercussão Geral no Recurso Extraordinário com Agravo n. 1.042.075-RJ, de relatoria do Ministro Dias Toffoli, recurso esse em fase de julgamento, reconheceu a repercussão geral em relação ao tema relativo a perícia realizada pela autoridade policial em aparelho celular encontrado no local do crime, com acesso à agenda telefônica e ao registro de chamadas sem autorização judicial.

No entanto, a tramitação da matéria na órbita do STF não afasta o interesse e a conveniência do estudo do tema sob os aspectos da privacidade e da comunicação, inclusive em relação à comunicação privada e à dirigida às massas, no sentido de verificar se a privacidade abarca os instrumentos que viabilizam a comunicação entre pessoas, em especial em relação ao aparelho celular

Estruturalmente, a pesquisa se inicia com a abordagem da comunicação privada e de massa; em seguida, faz uma digressão da proteção constitucional da privacidade por meio da tutela da comunicação no Direito Brasileiro; a seguir, trata da privacidade e sua relação com a comunicação, com foco no celular; na sequência, aborda a legitimidade do acesso às informações contidas no celular principalmente com base na jurisprudência; por fim, apresenta uma crítica à aplicação da privacidade no acesso às informações contidas no celular.

O método utilizado é o indutivo, com base na legislação, doutrina e jurisprudência.

\footnotetext{
${ }^{3}$ Conforme dispõe a Constituição Federal de 1988:

Art. 144. A segurança pública, dever do Estado, direito e responsabilidade de todos, é exercida para a preservação da ordem pública e da incolumidade das pessoas e do patrimônio, através dos seguintes órgãos:

IV - polícias civis;

$\mathrm{V}$ - polícias militares e corpos de bombeiros militares.

${ }^{4}$ A respeito da persecução penal pela Polícia, assevera Fernando da Costa Tourinho Filho (2012, p. 229): "A Polícia Judiciária exerce aquela atividade, de índole eminentemente administrativa, de investigar o fato típico e apurar a respectiva autoria. É o conceito que se infere do art. $4^{\circ}$ do CPP. Contudo, o art. 144, $\$ 1^{\circ}$, IV, e $\$ 4^{\circ}$, da CF distinguem as funções de apurar infrações penais e as de Polícia Judiciária. Já que houve tal distinção, é lícito afirmar, nos termos do $\$ 4^{\circ}$ do art. 144 da Lei Maior, que às Polícias Civis, dirigidas por Delegados de Polícia de carreira, incumbem, ressalvada a competência da União, as funções de investigar as infrações penais e sua autoria, bem como fornecer às Autoridades Judiciárias as informações necessárias à instrução e julgamento dos processos; realizar as diligências requisitadas pela Autoridade Judiciária ou Ministério Público; cumprir os mandados de prisão expedidos pelas autoridades competentes; representar ao Juiz no sentido de ser decretada a prisão preventiva ou temporária; representar ao Juiz no sentido de se proceder ao exame de insanidade mental do indiciado; cumprir cartas precatórias expedidas na
} 
Tem-se, como hipótese, que o acesso aos dados de aparelhos celulares apreendidos pela autoridade policial no exercício da persecução penal, está condicionado à prévia autorização judicial, embora em casos excepcionais seja admissível o acesso prévio ao conteúdo, com a obtenção de autorização judicial após a prática do ato, para efetivação de seu controle judicial, legitimando-se com isso a restrição ao direito fundamental à privacidade.

\section{COMUNICAÇÃO PRIVADA E DE MASSA}

A comunicação é uma liberdade que pode ser desenvolvida individual ou coletivamente. Para Pontes de Miranda (1974, p. 170), a natureza jurídica de liberdade de pensamento em relação à comunicação pode ser observada a partir da gradação: "liberdade de pensar, liberdade de não pensar; liberdade de emitir o pensamento, liberdade de não emitir o pensamento; liberdade de emitir o pensamento para todos, liberdade de só o emitir para alguns ou para alguém, ou para si mesmo". Esta gradação permite observar que a comunicação possui natureza jurídica de liberdade positiva de emitir o pensamento.

É fundamental distinguir a comunicação privada da pública ou dirigida às massas. A comunicação privada é desenvolvida entre pessoas, em que há o desejo ou a intenção de limitação de acesso ao conteúdo comunicado, não importando o ambiente em que ocorra, sendo irrelevante o instrumento em que se desenvolve, como celular, cartas, computador, ainda que os interlocutores não saibam que possuem privacidade, pois tal circunstância não afasta a proteção jurídica.

Há situações em que facilmente se observa o ânimo do comunicador pela discrição e não publicitação do conteúdo, pois ele manifesta a expectativa de privacidade sobre o conteúdo comunicado. A expectativa de privacidade é um elemento implícito à comunicação, somente sendo afastada quando voluntariamente o indivíduo fala ou dialoga para ou com o público, ou sabe que sua fala será divulgada ao público, situações que não estão abarcadas pela incidência de privacidade.

Segundo José Afonso da Silva (2007, p. 823) "toda manifestação ou exteriorização do pensamento é forma de comunicação que pode dar-se entre interlocutores presentes ou ausentes. No primeiro caso, pode verificar-se de pessoa a pessoa (em forma de diálogo, de conversação)", como a comunicação entre dois amigos, (pessoalmente ou via mensagem de celular), a comunicação realizada por um casal, a mensagem enviada por celular para um parente, o recado enviado via whatsapp para um amigo. "No segundo caso pode ocorrer entre pessoas determinadas, por meio de correspondência pessoal e particular sigilosa (carta, telegrama, telefone -

área da investigação criminal; colher a vida pregressa do indiciado; proceder à restituição, quando cabível, de coisas apreendidas, realizar as interceptações telefônicas, nos termos da Lei n. 9.296, de 24-7-1996 etc.”. 
ligados ao direito à privacidade, como foi visto)".

Quanto à comunicação dirigida às massas, há dois aspectos a serem considerados (SILVA, 2007, p. 823): a comunicação "destinada ao público geral, transmitida por processo ou veículo, dito, meio de comunicação social, (que) compreende a imprensa, o rádio e a televisão"; e a comunicação de "uma pessoa para outras (em forma de exposição, de conferência, palestras, discursos, livros, jornais, revistas e outros periódicos, etc.), interferindo aqui, com o direito de reunião e de associação" (SILVA, 2007, p. 823).

Dessa forma, é possível observar que na comunicação privada não se percebe um elemento fulcral existente na comunicação às massas, que é a destinação pública da comunicação. O que é comunicado está disponível a quem quiser e tiver acesso, não importando ao comunicador a restrição de acesso ao conteúdo daquilo que foi comunicado.

Diversamente ocorre com a comunicação privada, em que sempre se tem uma delimitação de acesso ao conteúdo daquilo que foi comunicado, portanto, uma demarcação do comunicador e do destinatário da conversação.

Constata-se, assim, a relevância da distinção entre a comunicação privada e a dirigida às massas, quando o assunto é aferir a incidência ou a ausência de privacidade sobre o conteúdo e os instrumentos viabilizadores da comunicação.

\section{A PROTEÇÃO CONSTITUCIONAL DA PRIVACIDADE E A TUTELA DA COMUNICAÇÃO}

A digressão da proteção constitucional da comunicação privada no Direito Brasileiro busca evidenciar que o legislador constitucional se preocupou em proteger tanto a comunicação privada como a dirigida às massas.

Historicamente, a tutela da comunicação privada foi prevista, direta ou indiretamente, em todas as Constituições brasileiras. Nas primeiras Constituições, a proteção se dava indiretamente, na forma de inviolabilidade da correspondência.

Nesse sentido, a Constituição Imperial de 1824, embora sem usar os termos intimidade e privacidade, tutelou o direito à inviolabilidade da correspondência, ao dispor no inciso XXVII do art. 179, que o segredo das cartas é inviolável. Ou seja, a Lei Maior previu a proteção ao direito à privacidade das pessoas, ainda que de forma indireta.

A Constituição Republicana de 1891 contemplou o direito à inviolabilidade da correspondência no $₫ 18$ do art. 72, ao assegurar que é inviolável o sigilo da correspondência aos brasileiros e estrangeiros residentes no país.

O Texto Constitucional de 1934 previu no $\$ 8^{\circ}$ do art. 113, que é inviolável o sigilo da correspondência. 
A Lei Maior de 1934 inovou no art. 114, ao prever que a especificação dos direitos e garantias expressos no texto constitucional não excluía outros direitos resultantes do regime e dos princípios adotados por ela.

A Constituição de 1937 dispôs de forma semelhante às Cartas Constitucionais anteriores, tutelando o direito de inviolabilidade ao sigilo da correspondência no artigo $122, \$ 6^{\circ}$.

A Carta de 1946 também seguiu a orientação firmada pelas Constituições que a antecederam, resguardando o direto à inviolabilidade da correspondência no art. $141, \$ 6^{\circ}$.

A Constituição de 1967 garantiu a inviolabilidade da correspondência no art. 150, $\mathbb{9} 9^{\circ}$, acrescentando, porém, a proteção ao sigilo das comunicações telegráficas e telefônicas.

A Constituição Federal de 1988 manteve os direitos que constavam da Constituição de 1967, relativos ao sigilo de correspondência e das comunicações telegráficas e telefônicas, com a novidade da inserção efetiva das expressões "intimidade" e "vida privada" no texto, evidenciando de forma direta o direito personalíssimo à privacidade (SARLET; MARINONI; MITIDIERO, 2017).

O fato de as Constituições anteriores à Carta de 1988 serem omissas em seus textos em referência direta à privacidade, ${ }^{5}$ não obstaculizou a sua proteção jurídica, isto porque a inviolabilidade da correspondência prevista desde a Constituição de 1824 demonstra que sempre houve a preocupação social em proteger a comunicação.

Os dispositivos constitucionais citados permitem sustentar que o sistema jurídico brasileiro possui a tradição de proteger a realização da comunicação. A proteção indireta à privacidade havida até a $\mathrm{CF} / 88$ por meio da tutela de objeto jurídico viabilizador da comunicação, como o sigilo de correspondência e a comunicação telefônica, sugere a fundamentalidade da privacidade para o desenvolvimento pessoal do indivíduo.

No tocante à privacidade e sua relação com a comunicação, há dois dispositivos que evidenciam o direito à privacidade, ou seja, o inciso X do art. $5^{\circ}$ da Constituição de $1988^{6}$ e o artigo 21 Código Civil de $2002 .{ }^{7}$

Assim, serão apresentadas reflexões sobre os dispositivos normativos mencionados, perpassando pela origem do direito à privacidade, evidenciando conceituações sobre a "intimidade" e a "vida privada, buscando demonstrar por que se entende como meio adequado a utilização do termo "privacidade" para a proteção jurídica conferida pelos dispositivos antes mencionados.

\footnotetext{
${ }^{5}$ Para Leonardo Cesar de Agostini (2011, p. 133): "Dada a ausência de expressa previsão constitucional constata-se facilmente nos comentários às Constituições precedentes à de 1988 que a maioria dos autores sequer se preocupou em delimitar o conteúdo de um direito à intimidade. É claro que os comentadores se referiam à proteção da intimidade. Entretanto essa referência se fazia de forma indireta tal como a inviolabilidade de correspondência, a inviolabilidade do domicílio mas, não, a um direito à intimidade propriamente dito".

${ }^{6}$ Estatui o inciso X do art. $5^{\circ}$ da Constituição Federal de 1988, que "são invioláveis a intimidade, a vida privada, a honra e a imagem das pessoas, assegurado o direito a indenização pelo dano material ou moral decorrente de sua violação”.

${ }^{7}$ Nos termos do art. 21 do Código Civil de 2002, "a vida privada da pessoa natural é inviolável, e o juiz, a requerimento do interessado, adotará as providências necessárias para impedir ou fazer cessar ato contrário a esta norma”.
} 


\section{A PRIVACIDADE E O CELULAR COMO MEIO DE COMUNICAÇÃO}

Basicamente, duas correntes de pensamento procuram definir a origem da intimidade. Uma delas, integrada por doutrinadores anglo-saxões como Alan Westin, Paul J. Muller e H.H. Kulmann, tem a intimidade como característica natural ou biológica do ser humano, que, em consequência, deve receber tutela jurídica. A outra, da qual são adeptos André Vitalis, Gérald Messadié, Stefano Rodotá, Perez Luño e L. Munford, entende que o reconhecimento do direito à intimidade é fundamentalmente consequência de fatores culturais e políticos (MELO, 2007, p. 67).

A partir destas formas de pensar, é possível entender que a intimidade é uma característica natural do ser humano, sem, no entanto, desconsiderar a ideia de que fatores culturais e políticos influenciam sua construção doutrinária e tratamento jurídico.

As expressões "intimidade", "vida privada" e "segredo" sugerem âmbitos diferidos de incidência, que parecem insuficientes a abarcar todas as situações e fatos que podem demandar a proteção jurídica.

Objetivando a apresentação de alternativas para a distinção entre as órbitaes de atuação da vida privada, da intimidade e do segredo, reporta-se à teoria dos círculos concêntricos, desenvolvida pelo jurista alemão Heinrich Henkel. Por esta teoria, que possui aplicação no Brasil, tem-se a vida privada como a de maior amplitude, comportando outras esferas menores, como a da intimidade, seguida pela esfera do segredo. O âmbito maior "seria abrangido pela esfera privada stricto senso. Nele estão compreendidos todos aqueles comportamentos e acontecimentos que o indivíduo não quer que se tornem do domínio público” (COSTAJUNIOR, 2007, p. 29).

Prossegue Paulo José da Costa Junior (2007, p. 30) afirmando que "no bojo da esfera privada está contida a esfera da intimidade ou esfera confidencial. Dela participam somente aquelas pessoas nas quais o indivíduo deposita certa confiança e com as quais mantém certa intimidade”. Ainda de acordo com o autor, como último âmbito de tutela, "no âmago da esfera privada, está aquela que deve ser objeto de especial proteção contra a indiscrição: a esfera do segredo", compreendendo a esfera "aquela parcela da vida particular que é conservada em segredo pelo indivíduo, do qual compartilham uns poucos amigos, muito chegados". Dessa esfera não participam sequer pessoas da intimidade do sujeito.

Todavia, há um campo não abrangido pela esfera da vida privada, é aquilo que pode ser denominado acessível ao público. Acham-se "eles ao alcance da coletividade em geral, de um círculo indeterminado de pessoas. E por estarem fora da esfera privada, tais fenômenos encontram-se juridicamente excluídos do campo dos chamados delitos de indiscrição" (COSTA JUNIOR, 2007, p. 29). 
Ainda que as proposições desta teoria não estejam livres de crítica, ${ }^{8}$ importa esclarecer que as distinções conceituais e os âmbitos diferidos de incidência, como intimidade, vida privada e segredo, possuem relevância para indicar a amplitude do direito à privacidade.

Em que pese a dificuldade em aferir um termo que confira maior adequação que as referências à “intimidade" e à "vida privada", é possível sustentar que uma compreensão adequada do inciso X do art. $5^{\circ}$ da $\mathrm{CF} / 88$, com reflexo no disposto no art. 21 do CC/02, contempla o direito à privacidade, ${ }^{9}$ isto porque o termo privacidade engloba um amplo conteúdo jurídico ${ }^{10}$, incluindo o que se entende por "intimidade", "vida privada" e "segredo", de forma que referidas expressões devem ser tidas como privacidade. Para Paulo José da Costa Junior (1993, p. 116), "o preceito constitucional foi redundante ao incluir, ao lado da intimidade, a vida privada, já que são conceitos idênticos. Tutelada a intimidade, estará automaticamente tutelada a vida privada do cidadão”.

Esta compreensão também pode ser sustentada a partir da constatação da utilização do termo privacidade por diversos Tribunais Jurisdicionais ${ }^{11}$ brasileiros.

Somente para efeito de argumentação, caso esta interpretação não seja acolhida, há que se ressaltar a

\footnotetext{
${ }^{8}$ De acordo com Danilo Doneda (2009), “os termos 'vida privada' e 'intimidade' fazem menção específica a determinadas amplitudes do desenvolvimento da proteção da privacidade, como a teoria dos círculos concêntricos de Heinrich Henkel, que apresentaram maior importância em um determinado contexto e momento histórico. Aplicá-las à atual problemática dos dados pessoais, por exemplo, somente poderia ser feito com um raciocínio extensivo - o que, por si só, mitigaria os pressupostos de sua existência”.

${ }^{9}$ Afirmam Ingo Wolfgang Sarlet, Luiz Guilherme Marinoni e Daniel Mitidiero (2017, p. 446): "Embora exista quem - no direito constitucional brasileiro e em virtude do texto da Constituição Federal - busque traçar uma distinção entre o direito à privacidade e o direito à intimidade, [...] aqui adotaremos uma noção abrangente, incluindo a intimidade no âmbito de proteção mais amplo do direito à vida privada (privacidade)". Portanto, é possível perceber que os referidos autores tratam as expressões intimidade e vida privada como sinônimas de privacidade.

${ }^{10}$ José Afonso da Silva (2007, p. 100), ao analisar o art. 5 X da CF/88 e considerar a imprecisão das terminologias "intimidade" e "vida privada", entende que a melhor expressão a ser utilizada é "privacidade", pela amplitude e generalidade do termo. A respeito, afirma o autor: "Por isso, preferimos usar a expressão "direito à privacidade", num sentido genérico e amplo, de modo a abarcar todas essas manifestações da esfera íntima, privada e da personalidade, que o texto constitucional em exame consagrou”. Por sua vez, Danilo Doneda (2009) assim se expressa: "utilizar o termo privacidade parece a opção mais razoável e eficaz. O termo é específico o suficiente para distinguir-se de outros termos com os quais eventualmente deve medir-se, como a imagem, honra ou a identidade pessoal; e também é claro bastante para especificar seu conteúdo, efeito da sua atualidade. Mas esta escolha não surge somente da fragilidade das demais; ela revela-se por si só a mais adequada - por unificar os valores expressos pelos termos intimidade e vida privada".

${ }^{11}$ Em pesquisa realizada no banco de dados virtual dos Tribunais de Justiça dos Estados de São Paulo, Paraná, Santa Catarina, Rio Grande do Sul, Rio de Janeiro, Mato Grosso, Amazonas e Pernambuco, buscando a menção à expressão "privacidade", a partir do campo "Ementa”, até a data de 03/12/2017, constavam: no TJ-SP, 1.433 acórdãos. No TJ-PR, 2.407 acórdãos; no TJ-SC, são 253 acórdãos; no TJ-RS, 6.950 acórdãos; no TJ-RJ, 84 acórdãos; no TJ-MT, 98 acórdãos; no TJ-AM, 8 acórdãos; já no TJ-PE, são 120 acórdãos. Dentre as milhares de referências à privacidade, as seguintes expressões precediam o termo: invasão de privacidade; violação à privacidade; lesão à privacidade; afronta à privacidade; ofensa à privacidade; prejuízo à privacidade; restrição à privacidade; redução na sua privacidade; renúncia da privacidade; afetação à privacidade; impacto na privacidade; comprometimento da privacidade; expôs sobremaneira à privacidade; menosprezando a privacidade; o problema da privacidade; princípio constitucional da privacidade; direito constitucional fundamental de privacidade, direito à privacidade; direito subjetivo à privacidade; tutela da privacidade; garantir a privacidade; alegações de privacidade; critérios de privacidade; preservação do sigilo à privacidade; assegurar a privacidade. Estas referências evidenciam a relevância e tradição que a expressão possui para o Direito Brasileiro.
} 
impossibilidade de qualquer gradação de importância sobre as expressões intimidade, vida privada e privacidade, razão pela qual se entende que o texto constitucional e o Código Civil conferiram proteção jurídica isonômica ${ }^{12}$ a todas as situações em que incide a privacidade.

Implica dizer que em uma situação fática em que não se adote a concepção de direito à privacidade, mas sim se trate como intimidade, vida privada ou segredo, não importa qual termo seja utilizado, a proteção jurídica será semelhante, isto porque o texto constitucional, ao dizer que "são invioláveis a intimidade, a vida privada", não trouxe qualquer distinção quanto à proteção. ${ }^{13}$

Importante destacar que aquilo que o indivíduo torna público não possui qualquer relação com a privacidade, de forma que divulgações de informações, fatos da vida pessoal em redes sociais e congêneres, não estão amparadas pela tutela da privacidade.Isso difere de algo íntimo compartilhado por um indivíduo a outro, em razão do vínculo da confiança entre ambos, situação que está abarcada pela privacidade, visto que a confiança entre ambos veda qualquer possibilidade de publicidade, que, ocorrendo sem autorização, implica em ilícito civil e às vezes até em ilícito penal.

Com tais percepções, o indivíduo inserido em uma sociedade que demanda múltiplos relacionamentos em variados ambientes, recorrentemente deseja o recato, a discrição, almeja não sofrer intromissões em sua privacidade sem a sua permissão. Esse anseio pode se dar em variados ambientes e situações. Se pensar na utilização do aparelho celular, instrumento utilizado diuturnamente para muitas atividades e finalidades, pode-se indagar: a proteção à privacidade conferida nos textos normativos contidos no art. $5^{\circ}$, inciso $\mathrm{X}$ da Constituição de 1988, e art. 21 do Código Civil, estende-se para o indivíduo que utiliza aparelho celular? Em sendo afirmativa a resposta, como se daria a relação entre a privacidade e esse instrumento de viabilização de comunicação? Para a solução do problema é preciso compreender que a privacidade acompanha o indivíduo onde quer ele esteja, de

\footnotetext{
${ }^{12}$ Por esta razão, aparenta ser desnecessária para fins da proteção jurídica conferida pelo art. $5^{\circ}, \mathrm{X}, \mathrm{da} \mathrm{CF} / 88$, a distinção entre intimidade e vida privada realizada por Leonardo Cesar de Agostini (2011, p. 129-130). O autor apresenta dois exemplos, sendo que apenas o primeiro é útil ao que ora se propõe: "Imagine-se que determinado profissional liberal se associa com outros profissionais da mesma área e passa a dividir o mesmo local de trabalho. Um certo dia, um de seus sócios, por pura curiosidade e se sentindo no 'direito' de compartilhar de todos os bens da sociedade, resolve acessar o conteúdo do computador do outro sócio, obtendo informação íntima que estava guardada naquele equipamento. Nesse caso hipotético a pergunta seria a seguinte: qual é o bem jurídico afetado? A intimidade ou a vida privada do indivíduo? A identificação parece ser de extrema relevância para que se dê resposta adequada ao caso, uma vez que se o sócio invasor argumentar que se eles dividem o mesmo espaço da vida privada do indivíduo afetado, a resposta a ser dada ao problema é a de que não haveria ofensa à privacidade daquele sócio que teve seu computador invadido. Por outro lado, se se entender que o bem jurídico afetado é a intimidade, e essa pode ser usufruída em qualquer local, o argumento passa a ser inválido e, a invasão arbitrária”. Todavia, o exemplo citado pressupõe que a vida privada não é usufruída em qualquer local, diversamente da intimidade, o que implica numa gradação da proteção jurídica, quando constitucionalmente o direito à privacidade é personalíssimo, acompanhando o indivíduo onde quer esteja.

${ }^{13}$ Importa esclarecer que sustentar que o texto constitucional apresenta distinção entre a intimidade e a vida privada, como referido por Luiz Alberto David Araújo e Vidal Serrano Nunes Júnior (2013, p. 200-201) e José Joaquim Gomes Canotilho, Gilmar Ferreira Mendes, Ingo Wolfgang Sarlet e Lenio Luiz Streck (2013, p. 277), não significa dizer que há distinção jurídica quanto à
} 
forma que muitas situações, ações e coisas vividas e utilizadas pelas pessoas estão afetadas pela privacidade, ${ }^{14}$ sendo inviável catalogar ou enumerar a amplitude de possibilidades de sua incidência. Todavia, é possível indicar algumas ocorrências de privacidade, dada a abrangência das facetas da relação da privacidade do indivíduo com as muitas situações, ações e coisas vividas e utilizadas pelas pessoas.

É relevante atentar para o fato de que a comunicação entre pessoas é situação que reclama relação direta com a privacidade, pois, ao dialogar e interagir um com o outro, há racionalização, filtragem de conteúdo, escolha sobre o que comunicar, e tais aspectos são indissociáveis da incidência de privacidade.

É preciso pensar na multiplicidade de ações que são realizadas em um aparelho de celular, como a comunicação em si (por áudio, vídeo), os inúmeros aplicativos (músicas, comunicação em redes sociais, bancários, anotações, fotografias), acesso à internet, sendo que tais ações normalmente revelam preferências e gostos individuais. Os celulares ainda guardam dados muito reservados (bancários, imagens, mensagens privadas), de forma que não há como sustentar que os celulares não são objetos de incidência de privacidade.

Essa abordagem permite perceber que os aparelhos celulares guardam uma relação visceral com a privacidade do dono do aparelho e até de terceiros, visto que, ordinariamente, quando acontece violação à privacidade do dono do aparelho, ocorre também vulneração à privacidade das pessoas que interagem com ele, pois os dados dessas pessoas serão também revelados.

Considerando esta relação entre o celular e a privacidade do seu titular e até de terceiros, pode-se indagar e refletir: a autoridade policial, quando aborda um indivíduo suspeito ou o prende em flagrante pela prática de ilícito penal, pode também apreender o aparelho celular e visualizar o seu conteúdo?

\section{LEGITIMIDADE DO ACESSO AS INFORMAÇÕES CONTIDAS NO CELULAR}

Sem dúvida, se alguém detém e acessa algo que pertence a terceiro, sem que haja o consentimento deste, a sensação é de desrespeito, invasão, irritação, indignação, enfim, é algo individualmente condenável, socialmente reprimível, juridicamente ilícito.

A questão que se coloca é saber se, independentemente do animus ${ }^{15}$ do indivíduo, a autoridade policial

proteção conferida por qualquer das referidas expressões, uma vez que a proteção jurídica é semelhante quando invocada qualquer das referidas expressões.

${ }^{14}$ A ressalva à incidência de privacidade se dá quando o indivíduo voluntariamente dialoga para ou com o público, ou sabe que sua fala será divulgada ao público, deste modo, é perceptível a renúncia da privacidade pelo indivíduo.

${ }^{15}$ Alegado o fato de constrangimento ilegal, a prova da sua inexistência é ônus do Estado, e não do indivíduo, isto porque, "quem tem o ônus da prova é quem acusa e não quem se defende. Isso é a base do sistema acusatório ou, se preferimos, do processo penal dos Estados Democráticos de Direito", conforme afirmado por Marcelo Cattoni em palestra da Unisinos e lembrado por Lenio Luiz Streck (2016). 
pode apreender o seu celular e devassar seu conteúdo.

Na dicção do art. $6^{\circ}$ do Código de Processo Penal (BRASIL, 1941), logo que tiver conhecimento da prática da infração penal, a autoridade policial deverá "apreender os objetos que tiverem relação com o fato, após liberados pelos peritos criminais" (inciso II), e "colher todas as provas que servirem para o esclarecimento do fato e suas circunstâncias" (inciso III).

Um aspecto a ser considerado da legislação, é que o indivíduo que é abordado e preso em flagrante delito pela prática de suposta infração penal estará sujeito à apreensão dos pertences que estiverem sob sua posse no momento da prisão. A redação do dispositivo normativo apresenta a determinação "deverá", portanto, deve a autoridade policial obedecer ao seu comando.

Outro aspecto pertinente a fortalecer a apreensão dos objetos em posse do indivíduo, está relacionado à formação das provas que servirão ao embasamento do processamento daquele que cometeu suposto ilícito penal, também por isso a importância da apreensão fundamentada pelo art. $6^{\circ}$, II do CPP.

Para Gustavo Henrique Badaró (2016) a autoridade policial deverá apreender os objetos e instrumentos do crime nos termos do (art. 60, II do CPP), sendo que no caso de objetos deixados no local do crime e que sejam de interesse da investigação, prescindível é o mandado judicial. Em relação à busca domiciliar e à busca pessoal, entende ser imprescindível o mandado judicial.

Portanto, para a realização dos desígnios estatais de combate e repressão à prática de ilícitos penais, visando garantir a segurança pública e com o intuito de embasar o processamento do suposto infrator da ordem jurídica, justifica-se a apreensão dos objetos relacionados ao fato criminoso.

Todavia, ressalte-se que a apreensão dos objetos de posse daquele que foi preso, ainda que respeitando a legislação processual penal, não significa dizer que haja autorização legal para acesso aos dados e informações constantes nos objetos apreendidos.

A compreensão do art. $6^{\circ}$, II e III do CPP, que deve ser feita conjuntamente com as normas constitucionais aplicáveis à matéria, permitirão a realização de uma análise sistemática dos dispositivos penais, considerando para tanto a unidade do Direito.

Conforme dispõe a Lei Maior (BRASIL, 1988): "são invioláveis a intimidade, a vida privada, a honra e a imagem das pessoas, assegurado o direito a indenização pelo dano material ou moral decorrente de sua violação" (art. 5o X); e, "é inviolável o sigilo da correspondência e das comunicações telegráficas, de dados e das comunicações telefônicas, salvo, no último caso, por ordem judicial, nas hipóteses e na forma que a lei estabelecer para fins de investigação criminal ou instrução processual penal” (art. 5, XII).

$\mathrm{O}$ art. $5^{\circ}, \mathrm{X}$ da $\mathrm{CF} / 88$, trata explicitamente do direito à privacidade, enquanto o art. $5^{\circ}$, XII da Lei Maior, dispõe sobre a inviolabilidade da correspondência, das comunicações telegráficas, de dados e das comunicações 
telefônicas.

$\mathrm{O}$ art. $5^{\circ}$, XII da CF $/ 88$ protege toda e qualquer forma de comunicação entre indivíduos, as quais está à primeira vista revestida de privacidade. A redação do art. $5^{\circ}$, XII da Lei Maior sugere a necessidade de haver reserva de jurisdição para que ocorra a relativização da privacidade contida nos aparelhos celulares e nos demais objetos que contenham informações privadas, o que em tese afastaria a possibilidade de a autoridade policial ter acesso ao conteúdo dos objetos apreendidos, imediata ou posteriormente à sua apreensão, sem autorização judicial.

Duas formas de pensar destacam-se a respeito da matéria, uma entendendo ser possível o conhecimento do conteúdo do celular pela autoridade policial sem autorização judicial, e outra sustentando que não é possível o acesso sem ordem judicial.

A primeira forma de pensamento entende ser viável o acesso ao conteúdo do celular pela autoridade policial, sem que haja reserva de jurisdição. Isso significa que o direito fundamental à privacidade (art. $5^{\circ}, \mathrm{X}$ da $\mathrm{CF} / 88$ ), que se estende a qualquer coisa ou objeto que armazene informações privadas da própria pessoa ou de terceiros, inclusive quando se trata de comunicação (art. $5^{\circ}$, XII da CF/88), estará sendo relativizado prévia e unilateralmente. Em outras palavras, a privacidade será afastada do seu titular, por consequência, estará sendo priorizada a persecução criminal e todos os seus desdobramentos, de modo que o interesse estatal encontrar-se-á privilegiado e garantido em tais circunstâncias, em detrimento ao direito à privacidade.

Esse entendimento, ainda que de forma não majoritária, tem sido adotado por alguns Tribunais Brasileiros nos casos de apreensão de aparelhos celulares por autoridades policiais, com base principalmente no art. $6^{\circ}$ do CPP.

Assim, quando do julgamento da Revisão Criminal n. 0077952-70.2014.8.26.0000, de relatoria do Des. Leme Garcia, em que a autoridade policial atendera chamadas recebidas em aparelho de telefone celular apreendido, sem prévia autorização para acesso ao aparelho, sendo que da verificação a polícia colheu os registros telefônicos do aparelho e os encaminhou para órgão de investigação, que então solicitou autorização judicial para interceptar os números relacionados no aparelho, tendo dessa operação resultado a constatação de que o acusado estava envolvido com a criminalidade, expressou-se o Relator, em manifestação acolhida pelo Tribunal de Justiça de São Paulo, no sentido de que "não configura quebra do sigilo de dados telefônicos a verificação direta pela autoridade policial das últimas chamadas efetuadas ou recebidas pelo agente, de modo que dispensável a autorização judicial na hipótese" (SÃO PAULO, 2017b).

No julgamento da Apelação n. 0000269-64.2016.8.26.0556, de relatoria do Des. Tristão Ribeiro, em que a autoridade policial analisou os dados do aparelho celular após a apreensão, sem que houvesse prévia ou posterior autorização judicial, tendo encontrado mensagens relacionadas com a comercialização de drogas, inclusive com fotografias, decidiu o Tribunal de Justiça de São Paulo pelo afastamento da alegação de nulidade das 
provas, sob o argumento de que a autoridade policial cumpriu seu dever, nos termos do art. $6^{\circ}$ do CPP (SÃO PAULO, 2017a).

Da mesma forma, o Tribunal de Justiça de Santa Catarina, ao julgar a Apelação n. 000006023.2016.8.24.0113, de relatoria do Des. Moacyr de Moraes Lima Filho, entendeu que o acesso e verificação de dados constantes no aparelho celular apreendido na prática de crime prescinde de autorização judicial (SANTA CATARINA, 2016b).

Em outo julgamento, o Tribunal de Justiça de Santa Catarina, ao julgar o Habeas Corpus n. 400250069.2016.8.24.0000, de relatoria do Des. Rui Fortes, entendeu que "a verificação de dados constantes em celular apreendido (chamadas, sms, whatsapp) não configura violação ao sigilo telefônico, pois, conforme o art. 6º II e III, do CPP, incumbe à autoridade policial colher todas as provas necessárias para elucidar a prática delituosa" (SANTA CATARINA, 2016a).

As decisões citadas indicam que o acesso aos dados de celular apreendido prescinde de autorização judicial, que é lícito à autoridade policial fazê-lo nos termos do art. $6^{\circ}$, II e III, e que tal acesso não constitui violação à privacidade, ao sigilo telefônico, nem interceptação telefônica, entendimento esse que acaba relativizando o direito à privacidade em face da persecução criminal.

Todavia, há uma segunda forma de pensar, no sentido de que a autoridade policial, no exercício da persecução penal, não está autorizada a devassar o conteúdo do aparelho celular e dos demais objetos que estão acobertados pela privacidade, sem que haja um controle judicial sobre esta ação estatal que avança sobre o direito fundamental à privacidade.

Nesse sentido, são expressivas as decisões dos Tribunais Brasileiros, inclusive do Superior Tribunal de Justiça, acolhendo essa forma de pensar, como se verifica dos julgados a seguir referidos.

Assim, o Tribunal de Justiça de Santa Catarina, ao julgar a Apelação n. 0000007-75.2016.8.24.0005, de relatoria do Des. Sérgio Antônio Rizelo, entendeu que "é necessário decretar a ilicitude das provas obtidas mediante a violação da intimidade e do sigilo de dados, consistentes em consulta ao histórico de mensagens existentes no aparelho celular apreendido com o Apelante, sem autorização judicial, nos termos dos arts. $5^{\circ}$, inc. LVI, da Constituição Federal e 157 do Código de Processo Penal” (SANTA CATARINA, 2016c).

O Superior Tribunal de Justiça, um dos órgãos de cúpula da Justiça Brasileira, não discrepa desse entendimento. Nesse sentido, ao julgar o Recurso Ordinário em Habeas Corpus de n. 51.531/RO, de relatoria do Min. Nefi Cordeiro, em que se discutia a legalidade da prova obtida a partir da transcrição de mensagens de texto gravadas em aparelho celular, apreendido e periciado pela autoridade policial sem autorização judicial, decidiu a Corte, por unanimidade de votos, que é "ilícita a devassa de dados, bem como das conversas de whatsapp, obtidas diretamente pela polícia em celular apreendido no flagrante, sem prévia autorização judicial”. Para o Ministro 
Relator, a apreensão do celular e a realização de perícia de seu conteúdo sem autorização judicial ferem os artigos $5^{\circ}$, incisos Xe XII da CF/88, o art. 3º inciso V, da Lei n. 9.472/97 (Lei das Telecomunicações) e o art. $7^{\circ}$ da Lei n. 12.965/14 (Marco Civil da Internet) e, embora possível o acesso ao celular e a seu conteúdo, para tanto é necessária prévia autorização judicial devidamente motivada (BRASIL, 2016).

Em síntese, enquanto para a primeira forma de pensamento há legitimidade em relação ao acesso ao aparelho celular, prescindindo-se da autorização judicial, para a segunda forma de entendimento, sufragada pelo Superior Tribunal de Justiça, a ausência da autorização judicial macula a legitimidade do acesso ao aparelho,

Todavia, a matéria ainda gera grande controvérsia, assim como não está estabilizada no âmbito da jurisprudência. Tanto é assim, que em 23-11-2017 o Supremo Tribunal Federal reconheceu a existência de repercussão geral da questão constitucional suscitada, relativamente ao tema concernente à perícia realizada pela autoridade policial em aparelho celular encontrado no local do crime, com acesso à agenda telefônica e ao registro de chamadas sem autorização judicial, por meio da Repercussão Geral no Recurso Extraordinário com Agravo n. 1.042.075-RJ, de relatoria do Ministro Dias Toffoli, recurso esse que se encontra em fase de julgamento.

\section{CRÍTICA A APLICAÇÃO DA PRIVACIDADE NO ACESSO ÀS INFORMAÇÕES CONTIDAS NO CELULAR}

O Poder Judiciário, como guardião da Constituição, "possui um papel estratégico nas democracias constitucionais contemporâneas - concretizando direitos fundamentais, intervindo, portanto, quase sempre na delicada relação entre direito e política" (STRECK, 2014, p. 329). É a instituição que, ao dirimir conflitos, atua imparcialmente, desinteressada em tomar partido por interesses contrapostos, cabendo-lhe o dever de garantir a correta aplicação do direito, ainda que para isso às vezes aja contramajoritariamente.

No acesso aos dados de aparelho celular quando da apreensão do equipamento por policiais, e na posterior discussão judicial acerca da validade das provas a partir destes dados, o Judiciário, como visto, às vezes tem interpretado o art. 5, X, XII da CF/88, de forma a restringir sua aplicação, limitando a irradiação dos seus efeitos, legitimando nesse contexto um acesso que viola tais preceitos constitucionais, o que enfraquece a proteção que estes dispositivos normativos reclamam do intérprete.

Os aparelhos celulares contemporâneos permitem uma gama de possibilidades de utilização, uma vez que são dotados de elevada capacidade de armazenamento de informações e amplas funcionalidades.

É de relevo enfatizar que os aparelhos celulares, antes de permitirem as muitas e variadas utilidades disponíveis, são fundamentalmente um instrumento de realização de comunicação, e comunicação entre indivíduos reclama privacidade. Portanto, não deve subsistir a relativização da incidência de privacidade sobre os 
aparelhos celulares sem que isso seja legítimo. Se tal ocorrer, estará sendo ofendido um direito que garante uma liberdade fundamental aos indivíduos, e sua admissibilidade implica em vulnerabilidade das pessoas frente à força da atuação estatal.

Vale consignar que não é a apreensão por suspeita ${ }^{16}$ de cometimento de ilícito ou mesmo a apreensão em flagrante delito que legitima o acesso ao conteúdo do aparelho celular pela autoridade policial, pois tais apreensões ${ }^{17}$ não significam autorização para acesso aos dados e à utilização destes, ao contrário, significam apenas a retenção do objeto, a sua guarda.

Porém, em sentido contrário, quando do julgamento da Apelação n. 0004260-38.2015.8.24.0039 pelo Tribunal de Justiça de Santa Catarina, expressou-se o Relator Roberto Lucas Pacheco nos seguintes termos (SANTA CATARINA, 2017):

O fato de os policiais terem acesso às mensagens de texto contidas no aparelho celular do apelante no momento em que efetuaram a prisão em flagrante não tem o condão de tornar inválida essa prova. As mensagens, imagens e demais dados constantes na memória do celular apreendido legalmente não estão ao abrigo do sigilo, motivo que afasta a hipótese de quebra ilegal de sigilo telefônico.

Por outro lado, como antes demonstrado, decisões com este teor não podem subsistir no Estado Democrático de Direito Brasileiro, pois violam a Constituição, afrontando o direito fundamental à privacidade.

Com isso, não se está afirmando que a autoridade estatal está proibida de acessar os dados constantes em aparelho celular apreendido, tornando a privacidade um direito absoluto. ${ }^{18} \mathrm{Na}$ verdade, é plausível a reflexão sobre a existência de situações que viabilizam o acesso pela autoridade policial a aparelho celular sem que haja autorização judicial. Não se nega que, ao menos em tese, existe essa possibilidade, dependendo da excepcionalidade do caso. Assim se verifica, por exemplo, quando há risco imediato à vida de alguém, como em crimes de sequestro, cárcere privado e tortura. Nestas situações, a autoridade policial, prendendo em flagrante um envolvido no crime e apreendendo seu aparelho celular, não está obrigada a aguardar o procedimento da reserva

\footnotetext{
${ }^{16}$ Importa ressaltar que a ocorrência de acesso aos dados de aparelho celular quando da apreensão do indivíduo seja por suspeita da prática de crime, ou mesmo quando da situação de flagrância, nestas hipóteses a relativização ao direito à privacidade ocorreria em momento preliminar a qualquer certeza estatal sobre a culpabilidade do indivíduo (art. $5^{\circ}$, LVII, da CF/88), pois, a devassa à privacidade nestas circunstâncias acontece ordinariamente no primeiro contato da autoridade policial com o indivíduo que supostamente cometeu o ilícito penal, deste modo, a garantia constitucional da privacidade restaria afrontada sem que o indivíduo tivesse oportunidade de qualquer defesa a esta intromissão - pois a intromissão é preliminar ao processamento.

${ }^{17}$ Não há dúvida da importância e relevância de que objetos apreendidos sejam utilizados como elementos de prova a corroborar para o processamento do indivíduo, todavia, em uma democracia é imprescindível o respeito às regras do jogo, lembrando pensamento (STRECK; MORAIS, 2014, p. 115).

${ }^{18}$ Sabe-se que em um sistema jurídico repleto de posições legais que podem conflitar entre si e reclamam por harmonia, não podese corroborar com a ideia de serem os direitos fundamentais absolutos, entendimento adotado pelo STF quando do julgamento do Mandado de Segurança n. 23.452-RJ (BRASIL, 2000), nos seguintes termos: "não há, no sistema constitucional brasileiro, direitos ou garantias que se revistam de caráter absoluto, mesmo porque razões de relevante interesse público ou exigências derivadas do princípio de convivência das liberdades legitimam, ainda que excepcionalmente, a adoção, por parte dos órgãos estatais, de medidas restritivas das prerrogativas individuais ou coletivas, desde que respeitados os termos estabelecidos pela própria Constituição".
} 
de jurisdição para ter acesso ao conteúdo do aparelho, pois a espera para a obtenção da autorização judicial provocaria um potencial risco à preservação da vida da pessoa.

Diante de tais fatos, acompanhando o raciocínio de Rafael Deus Garcia (2017), tem-se que o indivíduo preso em razão de envolvimento ou prática de crime que cause risco iminente à vida da vítima, como sequestro, violência doméstica e ainda outros crimes graves, pode ter o celular violado para averiguação pela autoridade policial, prescindindo-se da prévia autorização judicial.

Assim, se o atendimento ao procedimento de reserva de jurisdição inviabilizar ou impossibilitar o alcance da finalidade da atuação estatal, que é a proteção ao bem jurídico em risco pela prática do crime, justifica-se, devidamente fundamentada, a excepcionalidade da medida pela autoridade policial, consistente no acesso ao conteúdo do celular sem prévia autorização judicial.

Isso, porém, não significa a adoção do raciocínio de que os fins justificam os meios, pensamento esse finalístico e temerário no âmbito do Estado Democrático de Direito. No caso em questão, o procedimento realizado durante a persecução penal é apenas diferido, sendo a autoridade judiciária comunicada pela autoridade policial logo após a prática do ato de acesso ao aparelho celular e ao seu conteúdo

O que não se admite, é a ausência de procedimento que garanta a legitimidade ao acesso ao conteúdo do celular. Nesse contexto, entende-se que há legitimidade de acesso aos dados constantes nos aparelhos celulares, que são protegidos pela privacidade, quando a autoridade policial realiza requerimento prévio, ou posterior em casos excepcionais, à apreensão do objeto à autoridade judicial, e esta autoriza a prática ou concorda com a realização do ato, sendo então legítimo o acesso nessas hipóteses, isto porque houve a submissão do ato policial antecipado ou diferido, ao crivo da reserva da jurisdição.

Corroborando referido entendimento, como se infere do voto da Ministra Maria Thereza de Assis Moura, proferido quando do julgamento do Recurso Ordinário em Habeas Corpus n. 51.531-RO pelo Superior Tribunal de Justiça (BRASIL, 2016): o acesso das autoridades de persecução penal aos dados armazenados em aparelhos celulares de pessoas presas em flagrante é importante para o exercício do direito à segurança pública previsto no art. 144 da CF/88, norma que impõe ao Estado a obrigação de criar condições objetivas para o efetivo acesso ao serviço, inserindo-se entre tais condições a existência de mecanismos eficientes de investigação; havendo outro preceito constitucional em conflito com o direito à intimidade, no que se refere aos dados armazenados em aparelhos celulares, deve-se proceder a um processo de ponderação, que leve em consideração os interesses em jogo; nesse processo não se deve atribuir primazia absoluta a um ou a outro princípio ou direito, mas sim um esforço para assegurar a aplicação das normas conflitantes, ainda que uma delas venha a sofrer atenuação; a depender do caso concreto, caso a demora na obtenção de autorização judicial possa trazer prejuízos concretos à investigação ou em especial à vítima do delito, mostra-se possível admitir a validade da prova obtida 
por meio do acesso imediato aos dados do aparelho celular; com base no processo de ponderação dos interesses, é admissível o acesso imediato das autoridades policiais aos dados armazenados no aparelho celular, nos casos de urgência ou em caráter excepcional.

Em síntese, embora em regra o acesso aos dados de aparelhos celulares apreendidos pela autoridade policial no exercício da persecução penal exija prévia autorização judicial, em casos excepcionais é admissível o acesso ao conteúdo do aparelho, com a obtenção de autorização judicial imediatamente após a prática do ato, o que garante o respeito à Constituição Federal, legitimando-se assim a restrição ao direito fundamental à privacidade.

\section{CONCLUSÃO}

A pesquisa consistiu numa análise reflexiva e crítica em relação à aplicação dos dispositivos legais que tratam do direito à privacidade e do direito à segurança pública, principalmente o art. 5º X e XII, e o art. 144, ambos da Constituição Federal, e art. 6º II e III, do Código de Processo Penal, com ênfase à questão relativa à apreensão e acesso ao conteúdo de celular, pela autoridade policial, no exercício da persecução penal, sem prévia autorização judicial.

O ser humano é por natureza relacional, e para tanto faz uso da comunicação.

A comunicação entre as pessoas, em especial o ato de se expressar, normalmente sugere ligação com a privacidade, característica da natureza humana, pois para comunicar há racionalização, filtragem de conteúdo, enfim, escolha sobre o que e para quem comunicar.

A comunicação pode ser privada ou pública ou direcionada às massas. Enquanto na comunicação privada há o animus de discrição e restrição de acesso por terceiros ao conteúdo comunicado, na comunicação pública ou dirigida às massas não há o elemento da reserva ou restrição de acesso quanto a terceiros, ou seja, o conteúdo da comunicação é ou pode se tornar público.

A comunicação entre as pessoas, em especial o ato de se expressar, normalmente sugere ligação com a privacidade, característica da natureza humana, pois para comunicar há racionalização, filtragem de conteúdo, enfim, escolha sobre o que e para quem comunicar.

$\mathrm{O}$ direito à privacidade, tão relevante para a vida das pessoas, foi previsto, ainda que de forma indireta, em todos os Textos Constitucionais Brasileiros, normalmente por meio da proteção do direito à inviolabilidade da correspondência.

Atualmente, o direito à privacidade está erigido à natureza de direito fundamental, encontrando-se expressamente previsto no inciso X do artigo $5^{\circ}$ da Constituição Federal. 
O desenvolvimento tecnológico ampliou as formas possíveis de comunicação humana, estreitando os obstáculos "tempo e espaço". Entre outros instrumentos, o celular tornou-se um dos objetos mais populares e utilizados mundialmente para a comunicação entre as pessoas.

Os aparelhos celulares, por serem multifuncionais, abrigam inúmeras aplicações, informações, dados e interesses dos seus usuários, que estão abrigados por privacidade, o que torna o aparelho e seu conteúdo objeto da proteção jurídica conferida pelos artigos 5, Xe XII da Lei Maior.

A utilização dos aparelhos celulares se dá em variados contextos, como no privado, corporativo e público, assim como para propósitos lícitos ou ilícitos.

Por outro lado, a Constituição Federal garante a todos o direito à segurança pública (art. 144 da CF/88), e para a sua viabilização a legislação processual penal impõe à autoridade policial a apreensão de objetos que tenham relação com os fatos criminosos e a colheita de provas para elucidar tais fatos (art. 6º, II, III, do CPP).

A interpretação dos referidos dispositivos normativos permite concluir que é possível à autoridade estatal apreender os objetos que tenham relação com o fato suposta ou potencialmente criminoso. Todavia, há que se fazer a ressalva de que a apreensão do celular não significa intromissão, ingerência ou autorização para acesso aos seus dados ou conteúdo.

Há dois posicionamentos doutrinários básicos a respeito do acesso aos dados de celular apreendido por autoridades estatais no exercício da persecução penal: a primeira, sustentando que o acesso aos dados prescinde de autorização judicial, sendo lícito à autoridade policial fazê-lo, nos termos do art. $6^{\circ}$, II e III, do CPP, não implicando o acesso em violação à privacidade, ao sigilo telefônico ou à interceptação telefônica; a segunda, entendendo que a autoridade policial não está autorizada a devassar o conteúdo do aparelho celular, que está protegido pela direito fundamental à privacidade, salvo mediante prévia autorização judicial.

$\mathrm{Na}$ jurisprudência, inclusive do Superior Tribunal de Justiça, tem predominado o entendimento no sentido de que os aparelhos celulares estão abrigados pelo direito fundamental à privacidade, sendo que seus dados ou conteúdo somente podem ser acessados mediante prévia autorização judicial. Nos casos urgentes ou excepcionais, tem-se como admissível o acesso aos dados pela autoridade policial, sem prévia autorização judicial, devendo a autoridade policial, em seguida, submeter seu ato à reserva de jurisdição, objetivando o controle do mesmo sobre a ótica da constitucionalidade e da legalidade.

Tem-se, em conclusão, que restou demonstrada a hipótese inicial, no sentido de que o acesso aos dados de aparelho celular apreendido pela autoridade policial no exercício da persecução penal, inclusive no caso de prisão em flagrante do infrator, está condicionado à prévia autorização judicial, embora em casos urgentes ou excepcionais seja admissível o acesso sem anterior autorização, caso em que deverá ser informada a autoridade judicial logo que possível, para o exercício do controle do ato, legitimando-se assim a restrição exercida em relação 
ao direito fundamental à privacidade.

\title{
PRIVACY VS. PUBLIC SECURITY: ACCESS TO MOBILE DEVICE DATA BY THE POLICE AUTHORITY
}

\begin{abstract}
The research aims to analyze the relationship between the right to privacy and the right to public security, with emphasis on the apprehension and access to the mobile device data by the police authority, in the exercise of criminal prosecution without judicial authorization. The matter is current, important and controversial, also because the Federal Supreme Court, in the General Repercussion in Extraordinary Appeal with Appeal 1.042.075RJ, in the trial phase, acknowledged in 2017 the general repercussion in relation to the subject regarding the investigation carried by police in mobile devices found in crime scenes, with access to the phone book and call log without judicial authorization. The method used is the inductive, based on legislation, doctrine and jurisprudence. In conclusion, the access to mobile device data apprehended by the police authority in exercise of criminal prosecution, including in the case of red-handed arrest of the offender, is subject to prior judicial authorization, although in urgent cases it is admissible access without previous authorization, in which case the judicial authority should be informed as soon as possible to exercise control of the act, legitimating the constitutional restriction exercised in relation to the fundamental right to privacy.
\end{abstract}

Keywords: Access to Mobile Device Data; Communication; Right to Privacy; Right to Public Security; Privacy.

\section{REFERENCIAS}

AGOSTINI, Leonardo Cesar de. A intimidade e a vida privada como expressões da liberdade humana. Porto Alegre: Núria Fabris Ed., 2011.

ARAÚJO, Luiz Alberto David; NUNES JÚNIOR, Vidal Serrano. Curso de direito constitucional. 17. ed. São Paulo: Verbatim, 2013. 
BADARÓ, Gustavo Henrique. Processo penal. 2. ed. em e-book baseada na 4. ed. São Paulo: Revista dos Tribunais, 2016.

BRASIL. Constituição da República Federativa do Brasil de 1988. Disponível em: http://www.planalto.gov.br/ccivil_03/constituicao/constituicaocompilado.htm. Acesso em: 16 jun. 2017.

Decreto-lei n. 3.689, de 3 de outubro de 1941 - Código de Processo Penal. Disponível em: <http://www.planalto.gov.br/ccivil_03/Decreto-Lei/Del3689.htm>. Acesso em: 15 jan. 2018.

Superior Tribunal de Justiça. Recurso Ordinário em Habeas Corpus n. 51.531-RO. Ministro Relator Nefi Cordeiro. Brasília, DJe, 9 maio 2016. Disponível em: <http://www.stj.jus.br/SCON/jurisprudencia/toc.jsp?processo=51531\&\&b=ACOR\&thesaurus=JURIDICO $\& \mathrm{p}=$ true $>$. Acesso em: 28 jun. 2017.

Supremo Tribunal Federal. Mandado de Segurança n. 23.452-RJ. Ministro Relator Celso de Mello. Brasília: DJe, 12 maio 2000.2 Disponível <http://redir.stf.jus.br/paginadorpub/paginador.jsp?docTP=AC\&docID=85966>. Acesso em: 29 jun. 2017.

CANOTILHO, José Joaquim Gomes; MENDES, Gilmar Ferreira; SARLET, Ingo Wolfgang; STRECK, Lenio Luiz. Comentários à Constituição do Brasil. São Paulo: Saraiva/Almedina, 2013.

COSTA JUNIOR, Paulo José. As garantias do cidadão brasileiro no campo penal. In: TEIXEIRA, Sálvio de Figueiredo (Coord.). As garantias do cidadão na justiça. São Paulo: Saraiva. 1993.

O direito de estar só: tutela penal da intimidade. 3. ed. São Paulo: Revista dos Tribunais, 2007.

DONEDA, Danilo. A tutela da privacidade no Código Civil de 2002. Anima: Revista Eletrônica do Curso de Direito da Opet, v. 1, p. 89-100, 2009. Disponível em: < http://www.animaopet.com.br/pdf/animal/artigo_Danilo_Doneda_a_tutela.pdf $>$. Acesso em: 26 jul. 2017.

GARCIA, Rafael Deus. Pode a autoridade policial acessar os dados do celular do indivíduo sem autorização judicial? Revista Eletrônica Empório do Direito, 2017. Disponível em: $<$ http://emporiododireito.com.br/backup/pode-a-autoridade-policial-acessar-os-dados-do-celular-doindividuo-sem-autorizacao-judicial/>. Acesso em: 10 dez. 2017.

MELO, Bruno Herrlein Correia de. Fiscalização do correio eletrônico no ambiente de trabalho. Campinas: 
Servanda, 2007.

MIRANDA, Pontes. Comentários à Constituição de 1967: com a emenda no 1 de 1969. 2. ed. São Paulo: Revista dos Tribunais, 1974.

SANTA CATARINA. Tribunal de Justiça do Estado de Santa Catarina. Apelação n. 4002500-69.2016.8.24.0000. Relator Rui Fortes. Florianópolis: DJ, 28 jun. 2016a. Disponível em: <http://busca.tjsc.jus.br/jurisprudencia/integra.do?rowid=AABAg7AADAAFuxGAAT\&tipo=acordao_5\&nupr ocesso $=400250069.2016 .8 .24 .0000 \&$ cdprocesso $=\& \operatorname{arq}=p d f>$. Acesso em: 26 jun. 2017.

Tribunal de Justiça do Estado de Santa Catarina. Apelação n. 0000060-23.2016.8.24.0113. Relator Moacyr de Moraes Lima Filho. Florianópolis: DJ, 25 out. 2016b. Disponível em: $<$ http://busca.tjsc.jus.br/jurisprudencia/integra.dorowid=AABAg7AADAAIoL_771_991_AAR\&tipo=acordao _5\&nuprocesso=0000060-23.2016.8.24.01 13\&cdprocesso=\&arq=pdf $>$. Acesso em: 27 jun. 2017.

Tribunal de Justiça do Estado de Santa Catarina. Apelação n. 0000007-75.2016.8.24.0005. Relator Sérgio Antônio Rizelo. Florianópolis: DJ, 7 jun. 2016c. Disponível em: <http://busca.tjsc.jus.br/jurisprudencia/integra.do?rowid=AABAg7AADAAFm3tAAO\&tipo=acordao_5\&nup rocesso $=000000775.2016 .8 .24 .0005 \&$ cdprocesso $=\& a r q=p d f>$. Acesso em: 29 jun. 2017.

Tribunal de Justiça do Estado de Santa Catarina. Apelação n. 0004260-38.2015.8.24.0039. Relator Roberto Lucas Pacheco. Florianópolis: DJ, 23 fev. 2017. Disponível em: <http://busca.tjsc.jus.br/jurisprudencia/integra.do?rowid=AABAg7AADAANrrcAAT\&tipo=acordao_5\&nupr ocesso $=000426038.2015 .8 .24 .0039 \&$ cdprocesso $=\& a r q=p d f>$. Acesso em: 4 jul. 2017.

SÃO PAULO. Tribunal de Justiça do Estado de São Paulo. Apelação n. 0000269-64.2016.8.26.0556. Relator Tristão Ribeiro. São Paulo: DJe, 25 mai. 2017a. Disponível em: <https://esaj.tjsp.jus.br/cjsg/getArquivo.do?cdAcordao=10461796\&cdForo=0>. Acesso em: 25 jun. 2017.

Tribunal de Justiça do Estado de São Paulo. Revisão Criminal n. 0077952-70.2014.8.26.0000. Relator Leme Garcia. São Paulo: DJe, 20 jun. 2017b. Disponível em: <https://esaj.tjsp.jus.br/cjsg/getArquivo.do?cdAcordao=10531185\&cdForo=0>. Acesso em: 25 jun. 2017.

SARLET, Ingo Wolfgang; MARINONI, Luiz Guilherme; MITIDIERO, Daniel. Curso de direito constitucional. 6. ed. São Paulo: Saraiva, 2017. 
SILVA, José Afonso. Comentário contextual à Constituição. 4. ed. São Paulo: Malheiros, 2007.

STRECK, Lenio Luiz Hermenêutica e positivismo contra o estado de exceção interpretativo. Consultor Jurídico, São Paulo, 25 fev. 2016. Disponível em: < http://www.conjur.com.br/2016-fev-25/senso-incomumhermeneutica-positivismo-estado-excecao-interpretativo>. Acesso em: 26 jul. 2017.

STRECK, Lenio Luiz; MORAIS, José Luiz Bolzan de. Ciência política e teoria do Estado. 8. ed. Porto Alegre: Livraria do Advogado, 2014.

TOURINHO FILHO, Fernando da Costa. Processo penal. 34. ed. São Paulo: Saraiva, 2012.v. 1.

Trabalho enviado em 08 de abril de 2018

Aceito em 31 de julho de 2018 